\title{
Success for mouth cancer charity in Dundee
}

\section{Tovember 2016 was a successful Mouth Cancer Action Month in Dundee. Scottish charity Let's}

Talk About Mouth Cancer partnered with students from the University of Dundee Dental School in raising awareness of this disease.

The aim of the campaign was to target higher risk groups with messages about mouth cancer signs and symptoms as well as counselling on risk reduction. Participants were then taught how to self-examine and the importance of early presentation.

The enthusiasm of the dental students from all years was clear throughout November. Non-registered and irregular attenders were reached via the walk-in Dental A\&E clinic where 200 patients completed a survey on mouth cancer, before being shown how to self-examine.

In the main campaign week teams of final year students and core trainees participated in morning workshops designed to strengthen confidence in talking about mouth cancer and emphasise their responsibility to detect, refer and educate patients. In the afternoons this confidence was consolidated as the volunteers created and took their own targeted campaign to reach specific high-risk groups. Spread over Dundee these teams engaged university students, patients attending Ninewells Hospital, ethnic minorities at the Dundee International Women's Centre, and the general public on the high street.

Additionally a group of final year

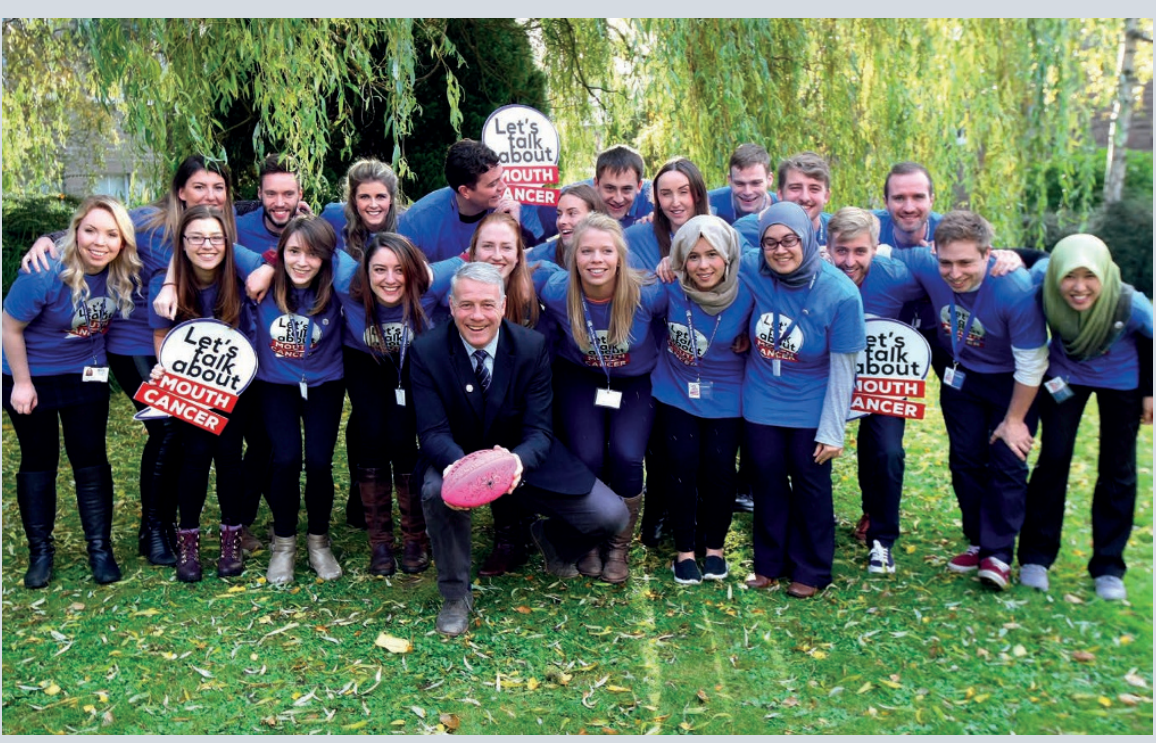

students on their own initiative took the campaign to Inverness where they were on outreach placement.

Public reaction was excellent, boosted by a visit from charity patron, former Scotland and British Lions rugby player, Scott Hastings. There was good press coverage and online social media engagement was fantastic; using the \#mouthcheck hashtag, the Facebook page had a reach in excess of 20,000 helped for good measure by on-trend videos: 'the mannequin challenge' received over 4,900 views and a student-led 'boomerang video' had 1,900 views.

Reflecting on the month's endeavours Stephanie Sammut, Let's Talk About Mouth Cancer Secretary and Consultant Oral Surgeon at Dundee Dental Hospital, said: 'Thanks to staff and students for the fantastic energy and enthusiasm shown throughout the Dental Hospital \& School. This action month wouldn't have been such a success without them. We should be proud of everyone's efforts to empower patients and the public in the fight against mouth cancer. We are already looking forward to our next event in Dundee!'

The campaign didn't stop in November; there are CPD lectures and other public engagement events planned for 2017. For more information see www.letstalkaboutmouthcancer.co.uk and to see the videos https://www.facebook.com/ letstalkaboutmouthcancer.

By Ewan MacKessack-Leitch, Trustee \& Treasurer, Let's Talk About Mouth Cancer

\section{Enormous support for mouth cancer message}

The Oral Health Foundation has hailed the impact that the 2016 Mouth Cancer Action Month campaign has had across all areas of the UK's healthcare industry.

As well as the enormous support that the campaign has once again received from the UK's dental community, the charity is particularly pleased with the strong support garnered from others areas of the healthcare industry, including pharmacies, general practices and maxillofacial surgeons.

CEO of the Oral Health Foundation, Dr Nigel Carter OBE, said: 'If people can access the information that could save their life through their doctor or pharmacy then it gives them a better chance of catching it early. At best people only visit their dental practice once every six months and in the times in between it can be very easy to overlook signs of mouth cancer and the disease progressing.

'That is why, during Mouth Cancer Action Month, we were delighted to see the incredibly strong support from across the healthcare industry and unprecedented amounts of information being distributed about the signs, symptoms and causes of mouth cancer.'

www.mouthcancer.org 